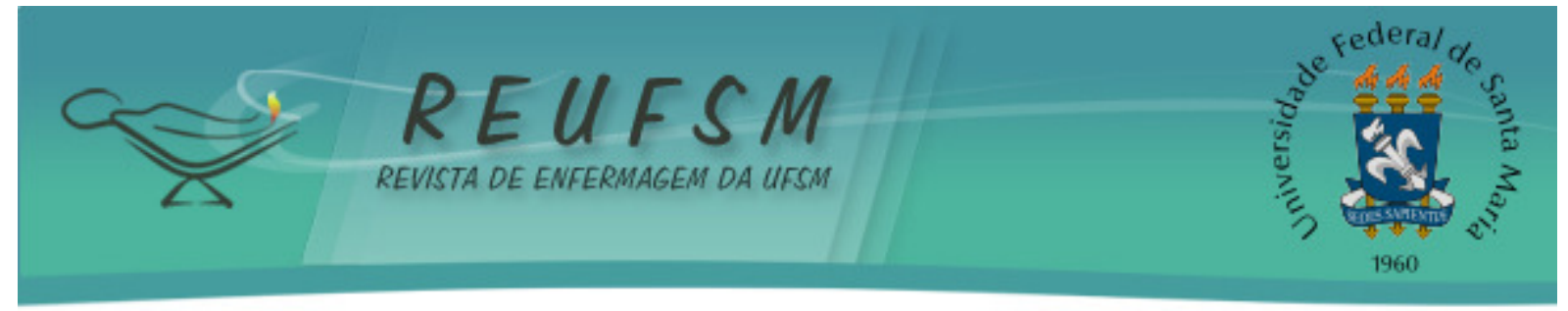

ARTIGO ORIGINAL

\title{
PERCEPÇÃO DO PACIENTE TRAUMATOLÓGICO ACERCA DA ASSISTÊNCIA PRESTADA DURANTE A HOSPITALIZAÇÃO
}

\author{
TRAUMA PATIENT'S PERCEPTION ON THE ASSISTANCE OFFERED DURING \\ HOSPITALIZATION
}

\section{PERCEPCIÓN DEL PACIENTE TRAUMATOLÓGICO ACERCA DE LA ASISTENCIA DURANTE LA HOSPITALIZACIÓN}

\author{
Nilton da Silva ${ }^{1}$ \\ Ruth Irmgard Bärtschi Gabatz ${ }^{2}$ \\ Renata Araújo Lemes ${ }^{3}$
}

Doi: $10.5902 / 2179769221306$

RESUMO: Objetivo: identificar a percepção do paciente traumatológico acerca da assistência prestada. Método: trata-se de uma pesquisa descritiva, cujos dados foram coletados entre agosto e outubro de 2015, abordando-se oito pacientes por meio da entrevista semiestruturada. Analisou-se as informações colhidas por meio da análise de conteúdo temática, criando-se três categorias: experiência com a lesão, percepção frente a hospitalização e assistência recebida pela equipe de saúde. Resultados: identificou-se a percepção positiva e a demonstração de surpresa em relação ao processo de tratamento do trauma durante hospitalização. Além disso, os pacientes se demonstraram satisfeitos quanto ao atendimento da equipe multiprofissional, principalmente no que se refere à comunicação eficiente e aos cuidados oferecidos. Considerações finais: a satisfação do paciente está relacionada aos recursos humanos e materiais disponíveis na unidade traumatológica, por isso é necessário oferecer, além de um cuidado de qualidade, uma infraestrutura adequada ao acolhimento do paciente e de seu acompanhante.

DESCRITORES: Traumatologia; Percepção; Cuidados de Enfermagem; Hospitalização.

ABSTRACT: Aim: to identify the trauma patient's perception about the offered assistance. Method: descriptive research, which data were collected from August to October, 2015, through semi-structured interviews with eight patients. The collected data were analyzed through thematic content analysis, from which three categories emerged: experience with the lesion, perception on hospitalization and assistance received by the health staff. Results: positive perception and demonstration of surprise regarding the trauma treatment process during hospitalization were identified. Besides, patients showed themselves satisfied regarding multiprofessional staff assistance, mainly referring to efficient communication and to the offered care. Final considerations: patient's satisfaction is related to human and material resources available in the trauma unit, that is the reason why it is necessary to offer, in addition to quality of care, an adequate infrastructure to welcome the patient and his/her companion.

DESCRIPTORS: Traumatology; Perception; Nursing care; Hospitalization.

\footnotetext{
${ }^{1}$ Enfermeiro graduado pela Faculdade de Enfermagem da Universidade Federal de Pelotas - UFPel, Pelotas, RS, Brasil. E-mail: niltonsilva6@live.com.pt

2 Enfermeira. Mestre em Enfermagem pela Universidade Federal de Santa Maria - UFSM. Professora Assistente da Faculdade de Enfermagem da Universidade Federal de Pelotas - UFPel, Pelotas, RS, Brasil. E-mail: r.gabatz@yahoo.com.br

3 Enfermeira. Especialista em Atenção à Saúde Cardiometabólica do Adulto pela Universidade Federal do Rio Grande - FURG. Enfermeira da Santa Casa de Misericórdia de Pelotas, Pelotas, RS, Brasil. E-mail: Im_renata@hotmail.com
} 


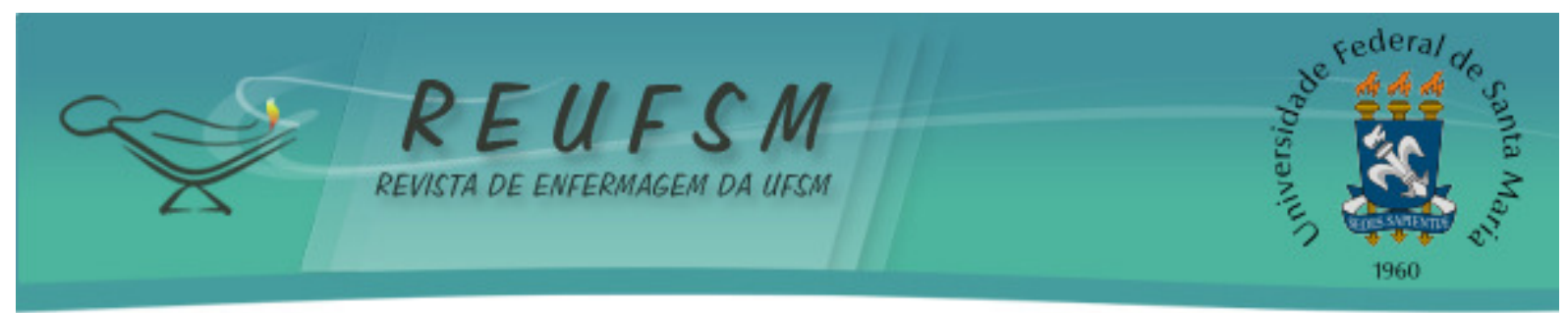

RESUMEN: Objetivo: identificar la percepción del paciente traumatológico acerca de la asistencia prestada. Método: trata de una investigación descriptiva, con datos recolectados entre agosto y octubre de 2015, con ocho pacientes entrevistados por medio de entrevista semiestructurada. Las informaciones recogidas fueron analizadas por medio del análisis de contenido temático y tres categorías fueron creadas: experiencia con la lesión, percepción frente a la hospitalización y asistencia prestada por el equipo de salud. Resultados: se identificó percepción positiva y demostración de sorpresa en relación al proceso de tratamiento del trauma durante hospitalización. Además, los pacientes demostraron satisfacción cuanto a la atención del equipo multiprofesional, principalmente en relación a comunicación eficiente y a los cuidados ofrecidos. Consideraciones finales: la satisfacción del paciente está relacionada a recursos humanos y materiales disponibles en unidad traumatológica, por eso es necesario ofrecer, además de cuidado de calidad, una infraestructura adecuada a acogida del paciente y de su acompañante.

DESCRIPTORES: Traumatología; Percepción; Atención de enfermeira; Hospitalización.

\section{INTRODUÇÃO}

A traumatologia trata de situações que podem levar a um longo período de permanência no ambiente hospitalar, comprometendo a mobilidade do paciente e causando restrições no desenvolvimento das suas atividades cotidianas. ${ }^{1}$ Desse modo, em unidades traumatológicas é necessário que a equipe de saúde esteja capacitada a assistir pacientes em condições complexas e que podem mudar rapidamente, por meio da oferta de um cuidado holístico e de qualidade. ${ }^{1}$

O paciente cirúrgico percebe a hospitalização como uma alteração do seu cotidiano, responsável por afetar seus hábitos e costumes, por afastá-lo do convívio de seus familiares e amigos, bem como da sua rotina de trabalho. ${ }^{2}$ Esses fatores contribuem para a geração de estresse e ansiedade no paciente, sendo transtornos potencializados pelo medo do desconhecido e pela falta de informações sobre sua condição e sobre os procedimentos aos quais será submetido. ${ }^{3}$ Nesse contexto ,é necessário que o enfermeiro conheça as expectativas do paciente traumatológico e ofereça orientações sobre normas e rotinas do local, disponibilizando-se para sanar as dúvidas sempre que necessário, a fim de diminuir a ansiedade e o estresse do paciente e de sua família. ${ }^{3}$

Sabe-se que a satisfação do paciente traumatológico com sua hospitalização está relacionada à expectativa criada por ele sobre a situação e sua percepção acerca do cuidado que recebe. ${ }^{4}$ Se o paciente é atendido por um profissional empático, que fornece orientações adequadas, ficará mais satisfeito e sua adesão ao tratamento será mais eficaz. ${ }^{5}$

Estudo $^{6}$ aponta que a percepção dos pacientes cirúrgicos com a hospitalização está relacionada com a atenção e o respeito dispensados a eles por enfermeiros e médicos e, também, com a performance da equipe no manejo da dor. Assim, quando a equipe atende às necessidades apresentadas pelo paciente, valorizando a subjetividade de cada um, a satisfação com a assistência recebida durante a hospitalização é maior. ${ }^{2}$

Nesse sentido, é imprescindível conhecer a perspectiva dos pacientes sobre a assistência que thes é oferecida, pois pode interferir na sua adesão ao tratamento e na sua reabilitação. ${ }^{7}$ Considerando esses pressupostos, a questão desta pesquisa foi: qual a percepção do paciente traumatológico sobre a assistência recebida durante a sua hospitalização? Neste estudo se objetivou identificar a percepção do paciente traumatológico acerca da assistência prestada durante a hospitalização. 


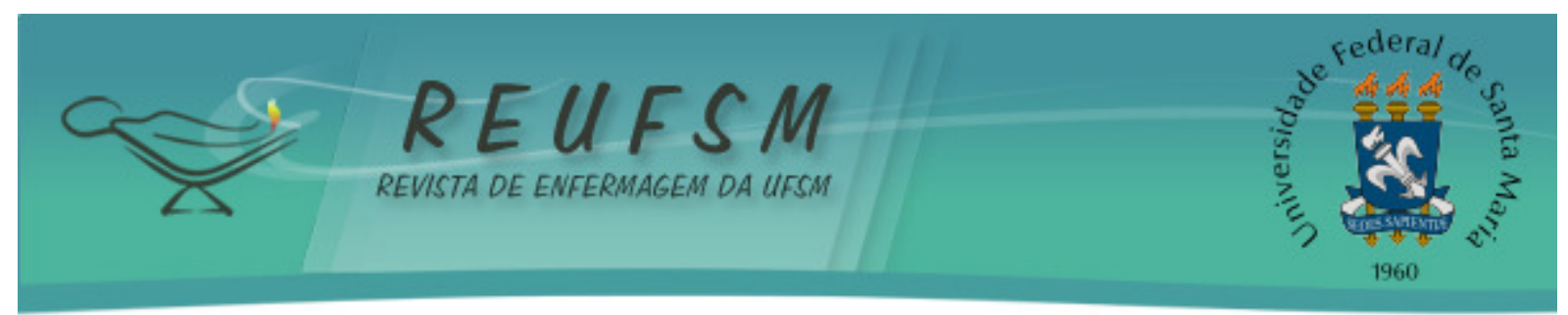

MÉTODO

Trata-se de uma pesquisa descritiva com abordagem qualitativa, cujos dados foram coletados em uma unidade de internação cirúrgica que atende pacientes vítimas de trauma físico, de um hospital de grande porte em um município do sul do Brasil, no período de agosto a outubro de 2015. A escolha desse local ocorreu porque ele possui um serviço de referência regional para tratamento de vítimas de trauma e, na unidade em questão, são internados os pacientes masculinos que necessitam de acompanhamento pelo Sistema Único de Saúde (SUS).

Participaram da pesquisa oito pacientes hospitalizados durante o período da coleta dos dados, tendo como critérios de inclusão: estar cognitivamente apto a responder à entrevista, ter sido vítima de trauma físico, estar internado no setor há, pelo menos, 48 horas e ser maior de 18 anos. Excluiu-se da pesquisa os pacientes que não haviam sido atendidos pela equipe de saúde completa (medicina, enfermagem e nutrição).

A coleta dos dados ocorreu por meio de uma entrevista semiestruturada contendo, além dos dados do perfil do paciente, quatro questões norteadoras que discorreram sobre a experiência do paciente com a hospitalização, sua percepção acerca da assistência prestada nesse período, sua compreensão sobre o processo de tratamento do trauma e sua satisfação com o cuidado recebido pela equipe de saúde. A duração média das entrevistas foi de 20 minutos, gravadas digitalmente e, posteriormente, transcritas para análise integral das informações. As entrevistas foram realizadas em uma sala privativa, individualmente, utilizando-se o princípio de saturação das informações como critério de delimitação da amostra. Assim, quando foi alcançada a redundância, ou seja, não surgiram novas informações, a coleta foi interrompida. ${ }^{8}$

Os pressupostos éticos contidos na Resolução 466/12 do Conselho Nacional de Saúde foram seguidos, respeitando-se a autonomia dos participantes. Após as orientações necessárias, com esclarecimentos sobre a natureza e o objetivo do estudo, os participantes aceitaram participar da pesquisa, mediante assinatura do termo de consentimento livre e esclarecido. ${ }^{9}$ Visando manter $\mathrm{o}$ anonimato, os participantes foram identificados pela letra $\mathrm{P}$ seguida por um número sequencial (P1, P2, P3).

Antes da coleta dos dados, o projeto foi encaminhado à plataforma Brasil, com aprovação sob o Certificado de Apresentação para Apreciação Ética número 47544115. 40000.5316, pelo Comitê de Ética da Faculdade de Enfermagem da Universidade Federal de Pelotas.

Os dados foram analisados por meio da análise de conteúdo temática, que consiste em descobrir os núcleos de sentido que compõem uma comunicação, conforme as seguintes etapas: pré-análise, exploração do material, tratamento dos resultados obtidos e interpretação. ${ }^{10} \mathrm{~A}$ partir da análise das informações foram criadas três categorias temáticas: experiência com a lesão, percepção frente à hospitalização e assistência prestada pela equipe de saúde.

\section{RESULTADOS E DISCUSSÃO}

Foram entrevistados oito pacientes hospitalizados, todos do sexo masculino, com faixa etária entre 19 e 64 anos. 0 grau de instrução dos participantes foi da segunda série do ensino fundamental até o ensino médio completo, no entanto, a maioria deles, cinco, possuía ensino fundamental incompleto. A renda familiar semanteve entre um e cinco salários, sendo que a metade dos participantes possuía renda de até dois salários mínimos.

No que se refere ao tipo de ferimento, sete dos oito participantes possuíam fratura em membros inferiores e um possuía fratura no polegar da mão direita. O tempo de 


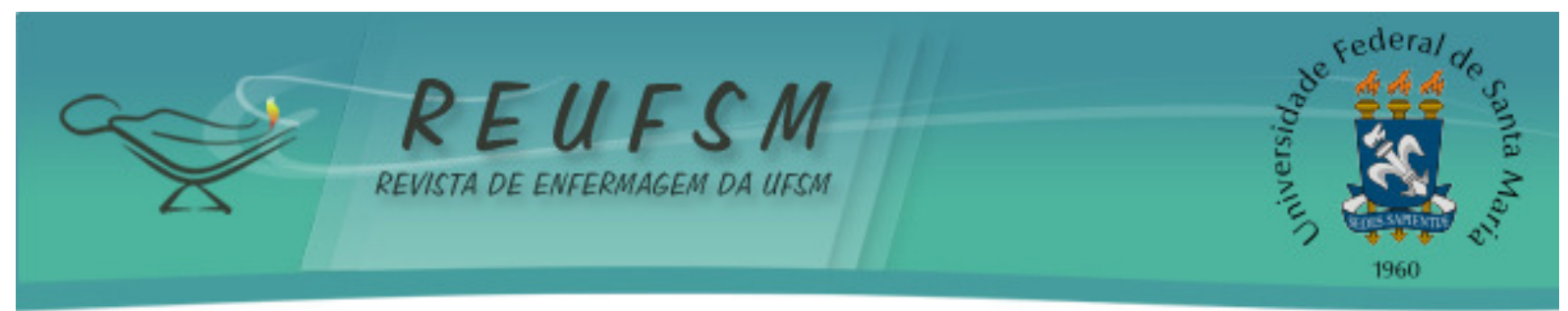

hospitalização, no momento da coleta das informações, variou entre dois e 27 dias, sendo que seis pacientes estavam hospitalizados há mais de sete dias. Todos os participantes pertenciam ao município em que o estudo foi realizado, em sua maioria de bairros distantes do centro da cidade.

\section{Experiência com a lesão}

Nesta categoria, são apresentados os resultados referentes às experiências que os participantes tiveram com a lesão, bem como as restrições impostas por elas. No relato de P1, fica evidente a limitação gerada pela fratura e a necessidade de se readequar para desenvolver as atividades diárias.

No caso tenho que usar prótese né, então vai ter alguma limitação, vou voltar a trabalhar, mas com certa limitação. Vou ter que me acostumar, não tem jeito. (P1)

As lesões geradas pelos traumas impactam a estrutura física e emocional dos pacientes, interferindo na sua qualidade de vida. ${ }^{11}$ Assim, a gravidade da lesão e a depressão, ocasionada por ela, interferem na reabilitação do paciente, limitando o desempenho das atividades cotidianas e restringindo a sua participação social. ${ }^{11-12}$ Além das restrições impostas pela lesão, é preciso estar preparado para enfrentar as sequelas que o acidente causou, conforme afirma P3.

Posso ficar até manco, meio que puxando uma perna por causa do acidente, porque ele provocou uma fratura, no caso, na coxa. [...] sequela a gente tem que estar preparado para aguentar agora depois do acidente [...] tu não espera e sabe que o corpo jamais vai ser como era antes. [...] Para mim está sendo um choque grande [...]. (P3)

Nesse depoimento, fica evidente a restrição física causada pela fratura na perna, além da mudança na imagem corporal, que pode interferir na autoestima e na aceitação do paciente. Diante de situações como esta, é necessário que o profissional de saúde esteja preparado para ajudar na aceitação da nova realidade, por meio de um cuidado empático que considere as necessidades individuais. ${ }^{7}$

Os problemas ortopédicos podem afetar padrões e papéis da vida do paciente, gerando restrições nas atividades cotidianas em variados graus e complexidade. Por isso, é necessário que a prática dos profissionais seja consciente e crítica, voltada às necessidades individuais. ${ }^{1}$

\section{Percepção frente à hospitalização}

Nesta categoria, são apresentados os depoimentos sobre as percepções dos participantes frente à hospitalização e às condições decorrentes dela. P4 aponta que ficou tranquilo com a necessidade da hospitalização, entretanto, espera que seja um período breve, pois nunca havia passado por essa experiência antes.

Fiquei até tranquilo, mais do que a minha mãe, que tomou um susto quando ficou sabendo que ia ficar internado, mas fiquei tranquilo, estou confiante, eu aceitei logo em seguida a internação. [...] Eu quero que seja rápido, [...] não quero ficar muito tempo 




aqui, [...] estou passando por tudo isso pela primeira vez, nunca estive dentro de um hospital, nunca machuquei nada. (P4)

Observa-se no relato acima que o familiar está diretamente envolvido com a hospitalização. Assim, a percepção da família acerca da necessidade de internação influencia na aceitação do paciente, bem como the impõe a condição de lidar com seus próprios sentimentos e com os sentimentos dos familiares. Quando um dos membros da família requer tratamento cirúrgico é preciso que ela se reorganize para poder criar estratégias de enfrentamento eficazes frente à magnitude do processo vivido. ${ }^{13}$ Por outro lado, P6 e P7 afirmam que apesar da hospitalização não ser uma experiência desejada, ela pode ser melhorada com um bom atendimento.

A sensação não é boa, ninguém gosta de estar dentro de hospital, mas pelo menos a gente está sendo bem atendido. (P6)

Foi muito bom até, sofri muito, senti muita dor, mas tudo que eles puderem fazer [...] para me ajudar, tirar a minha dor, eles me ajudaram. Pensei que ia ser pior, muita gente, mais machucado, correria, barulho, gente chorando e gritando, mas não. Tudo silêncio, foi tudo coordenado. (P7)

Percebe-se, na fala de P7, que, embora tenha passado por uma experiência desagradável, com muita dor, surpreendeu-se positivamente com o ambiente hospitalar, pois esperava que fosse mais barulhento e desorganizado. No entanto, alguns participantes destacaram o barulho no ambiente como um aspecto negativo da hospitalização, pois ele não permite ter um sono tranquilo para repousar.

Às vezes é muito barulho, zoeira, ninguém consegue descansar. Essa noite, por exemplo, eu não dormi, [...] às vezes chega paciente novo $e$ os acompanhantes ficam conversando entre um e o outro e a gente não consegue mais dormir. Esse é só um dos problemas que tem, assim, eu acho que é o mais grave, de não deixar o paciente descansar. (P6)

O descanso é muito importante para a reabilitação, por isso a equipe de saúde deve estar atenta à presença de ruídos, em especial, no período noturno, buscando controlá-los com o intuito de minimizar os efeitos negativos que podem produzir sobre o paciente. Os ruídos provocados, tanto por equipamentos - como bombas de infusão e telefones- quanto por risadas e conversas em voz alta, influenciam no processo de hospitalização, o que afeta a privacidade do paciente e pode prolongar sua permanência no hospital. ${ }^{14}$

Referente à infraestrutura encontrada na unidade em que estão hospitalizados, os participantes destacam como pontos positivos a limpeza do ambiente e dos lençóis, bem como a disponibilidade de alimentação, como explicitou P4:

em vista de muitos dos hospitais que têm por volta aí, a infraestrutura é boa, não tem o que reclamar, a cama é boa, os lençóis são limpos. Servem comida, servem café da manhã tudo do gosto da pessoa. Por enquanto até me surpreendeu um pouco, se tratando de SUS. (P4)

me surpreendeu. [...] Esperei que ia ser pior. (P5) 


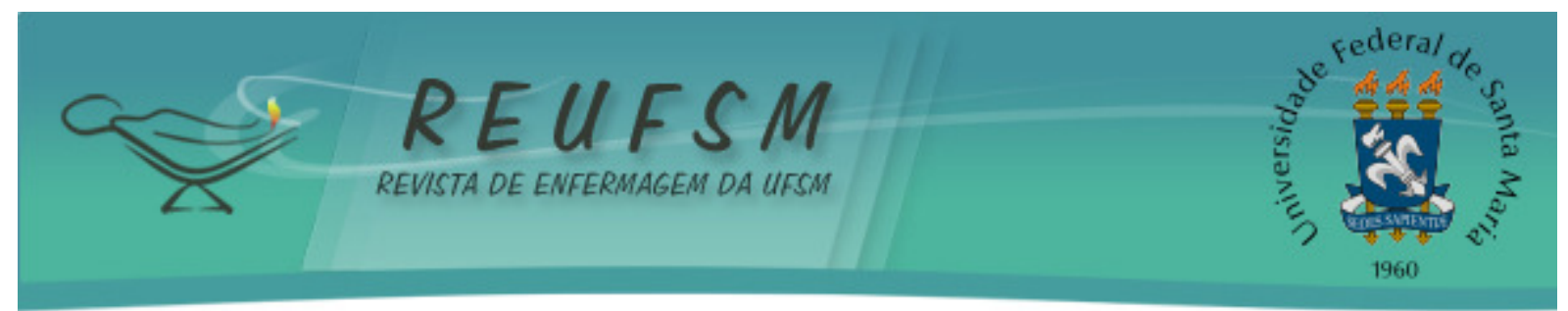

As afirmações dos participantes trazem um resultado importante no que diz respeito à imagem negativa construída pela população em relação à qualidade dos serviços oferecidos nos hospitais públicos. Existe um marketing negativo dos meios de comunicação em relação ao SUS, o que interfere na percepção da população frente à assistência prestada nos serviços públicos. ${ }^{15}$

Por outro lado, P6 destaca alguns pontos negativos que interferem na sua satisfação com a infraestrutura, como o tamanho da cadeira de banho e da poltrona para o acompanhante, além do piso escorregadio que pode provocar quedas.

A cadeira, por exemplo, que a gente usa aqui, eu não consigo entrar nela. Ela não entra no vaso, e outra, teria que ter as cadeiras que flexionassem as laterais para [...] poder abrir as pernas para [...] tomar banho [...]. As poltronas são ruins. [...] Outro aspecto é o chão, o chão da traumatologia é liso e escorregam as pessoas que andam de muleta, tinha que ser um antiderrapante. (P6)

As principais dificuldades vivenciadas pelos acompanhantes durante a sua permanência no hospital estão relacionadas à falta de estrutura física da maior parte das enfermarias, assim como condições pouco adequadas de repouso, alimentação e higiene, com pouco espaço para acomodação dos acompanhantes e falta de banheiros destinados a eles. ${ }^{16}$ Esses fatores podem restringir e dificultar a permanência dos familiares no ambiente hospitalar, cabendo aos profissionais de saúde pensar a respeito e implementar medidas capazes de garantir maior bem-estar aos acompanhantes dentro do hospital.

\section{Assistência prestada pela equipe de saúde}

Nesta categoria, apresenta-se os relatos sobre a percepção dos participantes quanto à assistência recebida durante a hospitalização. P1 destacou o cuidado recebido como sendo bom, fazendo-o se sentir em um ambiente acolhedor, enquanto P2 afirma estar feliz por causa do ótimo atendimento recebido.

Desde o primeiro dia eu até achei que aqui era um hospital particular. Eu fui muito bem recebido, tanto na hora da internação, antes de ir para cirurgia, quanto na hora de ir pra o leito. No geral, no caso as enfermeiras, são pessoas muito comunicativas, que se precisar, tanto de dia quanto de noite fora de hora, elas atendem a gente. [...] Elas atendem bem, não tem nada do que reclamar. (P1)

Até agora para mim está sendo excelente o atendimento mesmo, para mim até agora não tem nenhuma reclamação mesmo. [...] Por isso que para mim está sendo 10. [...] no quarto, aqui, estou feliz da vida, muito feliz mesmo porque o atendimento para mim foi maravilhoso, de todos eles. (P2)

A satisfação com a assistência recebida, nesses relatos, está relacionada ao interesse da equipe em estar ciente da condição de saúde do paciente e, também, dos cuidados prestados para a melhora do quadro. Uma assistência qualificada traz satisfação ao paciente, que pode vivenciar o período da hospitalização com menos estresse. Nesse 


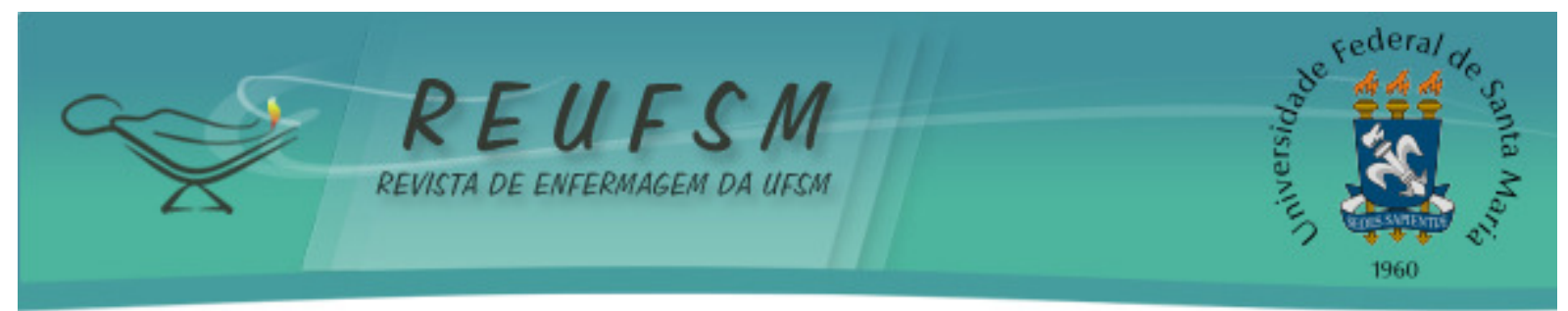

sentido, a satisfação com o cuidado prestado está associada ao levantamento das necessidades do paciente e à avaliação de sua condição física, emocional e social. ${ }^{17}$

0 vínculo profissional-cliente é um elemento fundamental para um bom atendimento e tratamento de saúde, bem como no reconhecimento de alterações relacionadas ao comportamento e às defesas do paciente, como angústia, raiva e impotência. ${ }^{18}$ Queixas e problemas de saúde dos usuários podem ser resolvidos ou atenuados se compreendidos e respeitados pelos profissionais de saúde. ${ }^{18}$ Assim, a empatia desses profissionais favorece a elaboração de um diagnóstico mais preciso, bem como a conformidade e a satisfação do paciente, sendo determinante para a qualidade no cuidado. ${ }^{7}$

$\mathrm{O}$ atendimento é percebido por P3 como carinhoso, de forma que ele sente que os profissionais são como seus familiares. Nesse contexto, a aproximação e a formação de vínculo auxiliam na confiança do paciente com o cuidado recebido.

Conversam, param aqui, conversam, perguntam como o paciente está, tratam com carinho, como se fosse um familiar da gente mesmo. Para mim uma surpresa muito boa. (P3)

Entende-se por acolhimento a adoção de uma postura de aproximação e de responsabilização durante o desenvolvimento das ações de atenção e gestão, favorecendo, dessa forma, a confiança e o compromisso entre usuários, equipes e serviços. Por outro lado, a falta de acolhimento pode levar ao abandono ou a não adesão ao tratamento. ${ }^{18-19}$

Características profissionais empáticas e a percepção da figura do enfermeiro como carinhoso, amigo e protetor favorecem a expressão de sentimentos positivos sobre o profissional. ${ }^{20}$ Assim, a empatia pode ser considerada uma palavra-chave em qualquer processo comunicativo, explicitando a sensibilidade emocional na relação interpessoal. ${ }^{21}$

Por outro lado, algumas condições, como a demora no tratamento, podem interferir na satisfação quanto à assistência recebida na hospitalização, como explicita P8:

poderia ser mais rápido a cirurgia, bem mais rápido, vai fazer 15 dias que eu estou aí, e não decidiram nada ainda. (P8)

A intervenção cirúrgica é definida como uma experiência geradora de ansiedade para o paciente, tanto em nível psicológico quanto fisiológico. Assim, estar inserido em um contexto desconhecido e incerto leva-o a se sentir inseguro. ${ }^{20}$ Muitas vezes, a falta de informação por parte dos profissionais de saúde acerca dos acontecimentos que sucedem cada uma das fases da cirurgia e as demais situações que a internação hospitalar proporciona são responsáveis por alterações de comportamento advindas dos pacientes. ${ }^{20}$

Sabe-se que a comunicação é muito importante para a prestação do cuidado. Nesse sentido, o relato de P1 mostra que a atitude da maioria dos profissionais da equipe de saúde é adequada para o contexto.

Os médicos vêm falar contigo no seu leito e perguntar como é que está, aí tu vai falar como é que tu está, entendeu? E se um certo tipo de remédio não está tendo tanta eficácia, aí eles procuram dar um reforço, outra alternativa, entendeu? (P1)

Nesse depoimento, evidencia-se que existe uma preocupação dos profissionais em prestar informações para esclarecimento de dúvidas, amenizando a ansiedade frente aos procedimentos realizados. Uma comunicação eficiente é indispensável para a satisfação do 


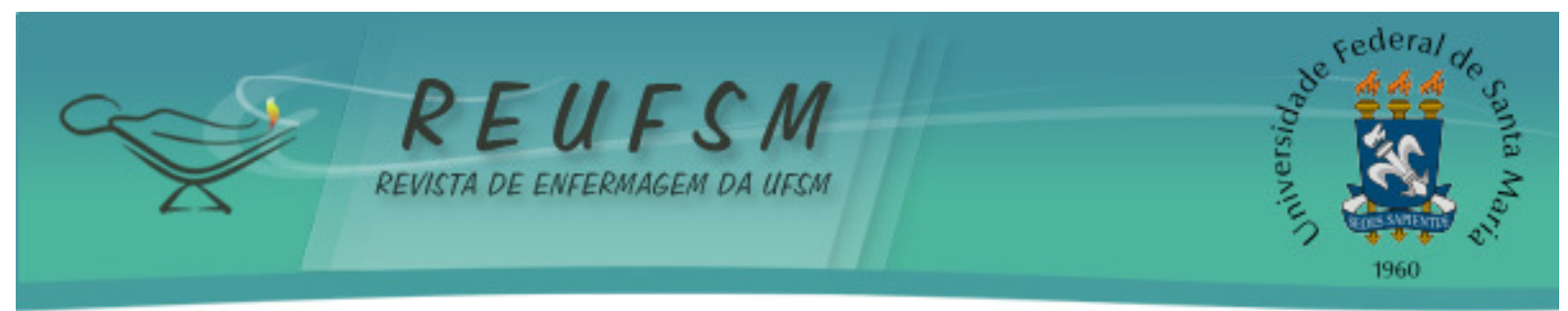

paciente com o cuidado que recebe, no entanto, é um processo que requer tempo e habilidade, ${ }^{7}$ além de ser preciso que o profissional ouça mais do que fale. ${ }^{21}$

A comunicação com a equipe de enfermagem tem um papel muito importante na assistência, pois é ela que passa mais tempo ao lado do paciente e seu atendimento requer um diálogo contínuo com ele. Nos relatos dos participantes se pode perceber o acompanhamento constante da enfermagem durante a hospitalização.

Conversei primeiro com a enfermeira, falou comigo, trata a gente super bem. Ela me perguntou o que é que eu tinha, [...] que fratura [...]. Pergunta se está doendo muito. (P5)

[...] ela buscou saber de tudo, como é que é antes de tudo, desde o que pode comer, teu alimento. [...] conversamos, boa a conduta deles. (P7)

Os relatos acima põem em evidência o quanto a comunicação favorece a percepção da assistência como qualificada, uma vez que a satisfação do paciente está relacionada à avaliação que faz do cuidado que recebe. ${ }^{21}$ Assim, pacientes e familiares ficam satisfeitos com o cuidado e as orientações da equipe de enfermagem quando têm suas expectativas atendidas. ${ }^{17}$ Nesse sentido, "o sentimento de ser bem cuidado é decorrente do processo de atendimento que o profissional faz quando é competente em comunicação". 17:636 Por outro lado, a falta de comunicação pode ser compreendida como ponto negativo na assistência recebida, como fica evidente na fala de P1 e P7.

[...] mas uma coisa que deixou a desejar foi a falta de comunicação, porque quando foram amputar parte do meu pé, até então não sabia que iam amputar. A princípio era apenas um curativo cirúrgico, mas ao chegar no bloco cirúrgico, os médicos entraram em consenso e disseram que teria que amputar. Acho que deveriam ter avisado antes. (P1)

Muito destas coisas eles não avisam. Chega e faz. [...] O certo era dialogar, conversar mais com as pessoas, até tranquilizava mais as pessoas. (P7)

Nesse relato, fica claro que a falta de comunicação pode interferir na aceitação do paciente frente a sua condição ou estado de saúde, impactando negativamente na percepção acerca da assistência recebida. Estudo ${ }^{3}$ aponta que muitos pacientes não são informados sobre o procedimento a que serão submetidos, o que gera uma maior preocupação e ansiedade pela falta de informação, bem como aumenta o estresse e os sentimentos negativos sobre sua situação. 0 período pré-operatório pode ser fonte de grande ansiedade e estresse, por isso, é importante que os profissionais utilizem uma comunicação adequada para possibilitar que o paciente assimile as orientações, a fim de minimizar as suas tensões emocionais. ${ }^{22}$

Um ponto que gera opiniões divergentes no contexto hospitalar é a alimentação oferecida: enquanto P2 refere ter gostado das refeições, P5 aponta que a alimentação poderia ser melhorada.

A comida é especial, também não tem o que a gente se queixar de nada, nada. (P2) 


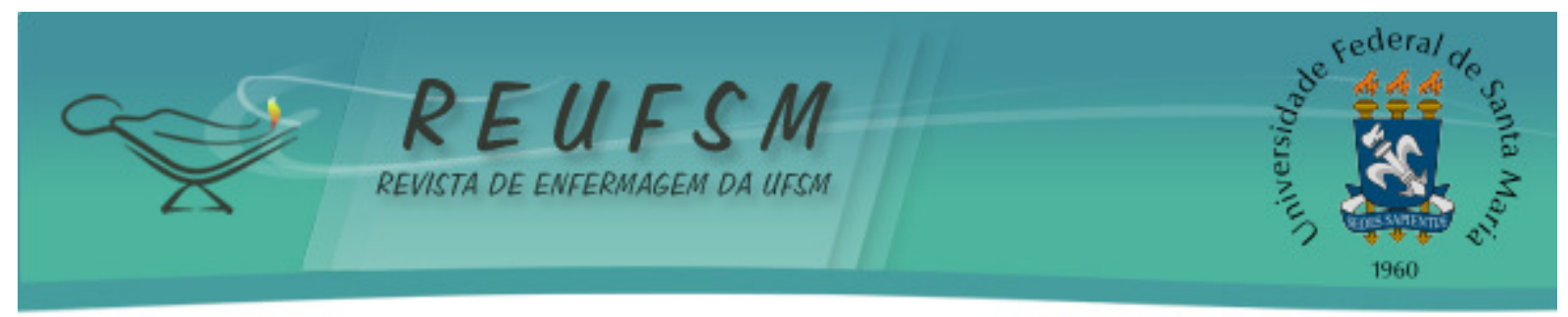

No caso a comida podia ser um pouco mais melhorada. (P5)

A alimentação fornecida no ambiente hospitalar é sempre um ponto de discussão quando se trata da satisfação dos pacientes, pois ela é bem diferente da dieta a qual o paciente está acostumado. As restrições alimentares impostas por certas condições de saúde, ou tratamentos como a cirurgia, que necessitam de um período de jejum antes do procedimento e um período de readequação após o procedimento, podem gerar insatisfação ao paciente e a seu familiar, sendo compreendidas como pontos negativos do cuidado recebido. Os pacientes não ingerem boa parte da alimentação que thes é oferecida no hospital em razão não apenas da doença, da falta de apetite e das alterações do paladar, mas também da mudança de hábitos e da insatisfação com as preparações e o ambiente hospitalar. ${ }^{23}$

Por fim, com base nos resultados deste estudo, percebeu-se a necessidade da equipe de saúde estar atenta às percepções do paciente traumatológico e de suas famílias acerca do processo de hospitalização, a fim de poder oferecer um cuidado de qualidade e adequado às necessidades específicas de cada indivíduo. Para tanto, é imprescindível adotar ações humanizadas, embasadas na criação de vínculos e na empatia, atendendo às necessidades expressas pelos pacientes e à realidade da equipe. ${ }^{2}$ Destaca-se, ainda, a necessidade de fornecer informações e orientações sobre todas as etapas de tratamento do trauma ao paciente e à sua família, para amenizar as dificuldades e as angústias enfrentadas no processo de hospitalização.

\section{CONSIDERAÇÕES FINAIS}

Considera-se que o objetivo proposto foi alcançado, pois foi possível identificar a percepção que os pacientes tiveram em relação à assistência prestada durante a hospitalização, sendo que eles se mostraram surpresos com a assistência recebida. A satisfação dos pacientes que participaram desta pesquisa esteve diretamente relacionada com os recursos humanos e materiais disponíveis na unidade traumatológica, por isso é necessário oferecer, além de um cuidado de qualidade, uma infraestrutura adequada ao acolhimento do paciente e de seu acompanhante.

A comunicação esteve relacionada com a percepção de qualidade no atendimento da equipe multiprofissional, sendo que quando ela não foi efetiva, contribuiu negativamente sobre a satisfação do paciente traumatológico. Nesse contexto, é importante que o profissional de saúde esteja atento às estratégias de comunicação utilizadas, bem como a sua efetividade, com a intenção de proporcionar um cuidado integral e humanizado.

As limitações do estudo se relacionam à realidade específica a qual se refere e ao pequeno número de participantes que a pesquisa qualitativa aborda, que não aspira generalizações. Entretanto, acredita-se que, na realidade local, esta pesquisa possa contribuir para compreender e melhorar a assistência ao paciente, de maneira a minimizar o impacto negativo causado pelo trauma e pela hospitalização, por meio de uma maior atenção à infraestrutura e ao fornecimento de informações sobre o tratamento e os procedimentos a serem realizados.

O estudo aponta para importantes implicações na assistência prestada pela enfermagem, como a elaboração de um plano de cuidados que considere as especificidades de cada paciente e sua família. Assim, os acompanhantes também devem ser inseridos nos cuidados, além de serem informados sobre todas as etapas do tratamento do paciente. 


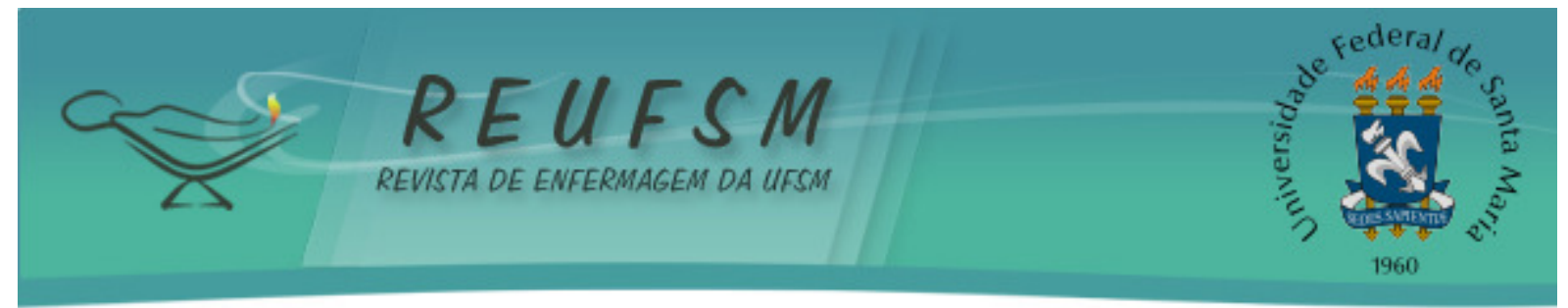

Sugere-se a realização de mais estudos com o paciente traumatológico, incluindo também os seus familiares, visando conhecer as implicações da hospitalização sobre a dinâmica familiar.

\section{REFERÊNCIAS}

1. Cameron LE, Araújo STC. Visão como instrumento da percepção na assistência em enfermagem traumato-ortopédica. Rev Esc Enferm USP.2011;45(1):95-9.

2. Piexak DR, Ferreira CLL, Terra MG, Backes DS, Barlem JGT, Itha S. Cuidado de enfermagem em unidade de internação cirúrgica: percepção dos pacientes. Rev Pesqui Cuid Fundam [Internet]. 2016 [acesso em 2016 jul 1];8(1):3624-32. Disponível em: http://www.seer.unirio.br/index.php/cuidadofundamental/article/view/3596/pdf_1766.

3. Barbosa AC, Terra FS, Carvalho JBV. Humanização da assistência médica e de enfermagem ao paciente no perioperatório em um hospital universitário. Rev Enferm UERJ. 2014;22(5):699-704.

4. Rodrigues AVD, Vituri DW, Haddad MCL, Vannuchi MTO, Oliveira WT. Responsividade do serviço de enfermagem na visão do cliente. Rev Esc Enferm USP. 2012;46(6):1446-52.

5. Santos MRM, Sousa CS, Turrini RNT. Percepção dos pacientes submetidos à cirurgia ortognática sobre o cuidado pós-operatório. Rev Esc Enferm USP. 2012;46(N Esp):78-85.

6. Hanna MN, González-Fernández M, Barret AD, Williams KA, Pronovost P. Does patient perception of pain control affect patient satisfaction across surgical units in a tertiary teaching hospital. Am J Med Qual [Internet]. 2012 [acesso em 2016 jun 29];27(5):411-6. Disponivel em: http://ajm.sagepub.com. doi: 10.1177/1062860611427769.

7. Steinhausen S, Omnen O, Thüm S, Leferin R, Koehler T, Neugebauer E, et al. Physician empathy and subjective evaluation of medical treatment outcome in trauma surgery patients. Patient Educ Couns [Internet]. 2014 [acesso em 2016 jun 13];95(1):53-60. Disponivel em: http://www.pec-journal.com/article/S0738-3991(13)00521-1/pdf. Doi: 10.1016/j.pec.2013.12.007.

8. Polit DF, Beck CT. Fundamentos de pesquisa em enfermagem: avaliação de evidências para a prática de enfermagem. $7^{a}$ ed. Porto Alegre (RS): Artmed; 2011.

9. Brasil. Ministério da Saúde. Conselho Nacional de Saúde. Resolução CNS n466, de 12 de dezembro de 2012. Aprova diretrizes e normas regulamentadoras de pesquisas envolvendo seres humanos [Internet]. 2012 [acesso em 2015 maio 24]. Disponível em: http://conselho.saude.gov.br/resolucoes/2012/Reso466.pdf.

10. Minayo MCS. O desafio do conhecimento: pesquisa qualitativa em saúde. $14^{\mathrm{a}}$ ed. São Paulo (SP): Hucitec; 2014.

11. Lugo-Agudelo LH, Salinas-Durán F, Cano-Restrepo BC, Cortés-García D, Córtes-García G, García-García HI. Calidad de vida y reinserción al trabajo en pacientes con trauma moderado y grave por accidentes de tránsito en Medellín (Colombia). Rev Gerenc Políticas Salud [Internet]. 2015 [acesso em 2016 ago 16];14(28):88-96. Disponivel em: www.scielo.org.co/pdf/rgps/v14n28/v14n28a07.pdf. doi: 10.11144/javeriana.rgyps1828.CVrt.

12. Sánchez-Vallejo PG, Pérez-Núñez R, Herredia-Pi I. Costo económico de la discapacidad causada por lesiones de tránsito em México durante 2012. Cad Saúde Pública. 2015;31(4):755-66. 


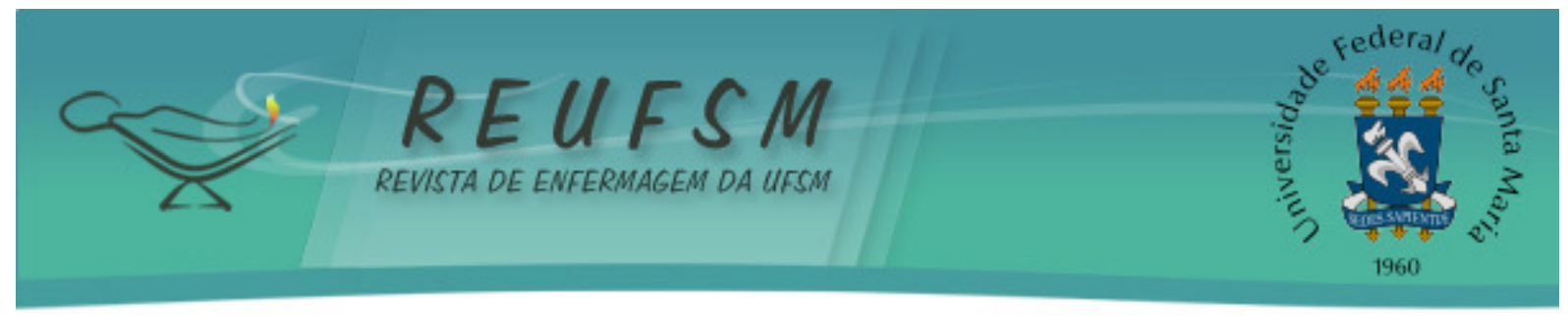

13. Morales LAL, Rey MCPA. Familias con adultos quirúrgicos: riesgo y salud familiar. 20072010. Av Enferm. 2013;31(1):22-31.

14. Chavaglia SRR, Borges CM, Amaral SEM, Iwamoto HH, Ohl RIB. Ambiente do centro de terapia intensiva e o trabalho da equipe de enfermagem. Rev Gaúch Enferm. 2011;32(4):654-61.

15. Souza PC, Scatena JHG. Satisfação do usuário da assistência hospitalar no mix públicoprivado do SUS do Estado do Mato Grosso. Espaç Saúde [Internet]. 2014 [acesso em 2016 ago 16];15(3):30-41. Disponível em: www.uel.br/revistas/uel/index.php/espacoparasaude/article/view/18048/pdf_38.

16. Sanches ICP, Couto IRR, Abrahão AL, Andrade M. Acompanhamento hospitalar: direito ou concessão ao usuário hospitalizado? Ciênc Saúde Coletiva. 2013;18(1):67-76.

17. Razera APR, Braga AEM. A importância da comunicação durante o período de recuperação pós-operatória. Rev Esc Enferm USP. 2011;45(3):632-7.

18. Camilo SO, Majorino FT. A importância da escuta no cuidado de enfermagem. Cogitare Enferm [Internet]. 2012 [acesso em 2016 fev 22];17(3):549-55. Disponível em: http://ojs.c3sl.ufpr.br/ojs2/index.php/cogitare/article/view/27826/19049.

19. Dal Pai D, Lautert L. Sofrimento no trabalho de enfermagem: reflexos do "discurso vazio" no acolhimento com classificação de risco. Esc Anna Nery Rev Enferm. 2011;15(3):524-30.

20. Costa VASF, Silva SCF, Lima VCP. O pré-operatório e a ansiedade do paciente: a aliança entre o enfermeiro e o psicólogo. Rev SBPH. 2010;13(2):282-98.

21. Calvo EMM, González MCG, Barceló LAL, Bencomo KR. Barreras de comunicación em la relación tecnólogo-paciente em el contexto professional. Humanidad Med [Internet]. 2013 [acesso em 2016 jun 13];13(1):38-55. Disponível em: http://www. scielo.sld.cu/pdf/hmc/v13n1/hmc04113.pdf.

22. Perrando MS, Beuter M, Brondani CM, Roso CC, Santos TM, Predebon GR. O preparo pré-operatório na ótica do paciente cirúrgico. Rev Enferm UFSM [Internet]. 2011 [acesso em 2016 jul 1];1(1):61-70. Disponível em: http://periodicos.ufsm.br/reufsm/article/view/2004/1512.

23. Sousa AA, Gloria MS, Cardoso TS. Aceitação de dietas em ambiente hospitalar. Rev Nutr. 2011;24(2):287-94.

Data de recebimento: 08/03/2016

Data de aceite: 23/08/2016

Autor correspondente: Ruth Irmgard Bärtschi Gabatz.

E-mail: r.gabatz@yahoo.com.br

Endereço: Rua Barão de Santa Tecla, 601 apto 402, Centro, CEP 96010-140, Pelotas/RS, Brasil. 